\title{
Prognostic indicators of pulmonary metastasis in patients with renal cell carcinoma who have undergone radical nephrectomy
}

\author{
JA YOON KU ${ }^{1,2^{*}}$, SUK KIM $^{3}$, SEUNG BAEK HONG ${ }^{3}$, JONG GEUN LEE ${ }^{4 *}$, \\ CHAN HO LEE ${ }^{5}$, SEOCK HWAN CHOI ${ }^{6}$ and HONG KOO HA ${ }^{1,2}$
}

\begin{abstract}
${ }^{1}$ Department of Urology; ${ }^{2}$ Biomedical Research Institute; ${ }^{3}$ Department of Radiology, Pusan National University Hospital, Pusan National University School of Medicine, Busan 49241; ${ }^{4}$ Department of Thoracic and Cardiovascular Surgery, Jeju National University Hospital, Jeju National University School of Medicine, Jeju 63241; ${ }^{5}$ Department of Urology, Busan Paik Hospital, College of Medicine, Inje University, Busan 47392; ${ }^{6}$ Department of Urology, School of Medicine, Kyungpook National University, Daegu 41944, Republic of Korea
\end{abstract}

Received February 21, 2018; Accepted November 26, 2018

DOI: $10.3892 / 01.2019 .9912$

\begin{abstract}
The aim of the present study was to validate prognostic indicators of pulmonary metastasis in patients with renal cell carcinoma (RCC) that have undergone nephrectomy treatment. The data from 356 patients who underwent nephrectomy were investigated and subsequently divided into 2 groups, according to the pulmonary metastasis status. The risk factors for pulmonary metastasis were examined in all patients. In the subgroup analysis, the risk factors were additionally verified in patients with pulmonary nodules using univariate and multivariate logistic regression analyses. The status of pulmonary nodules and pulmonary metastasis were confirmed through preoperative chest radiography by two radiologists. Pulmonary metastasis was observed in 33 (9.3\%) patients with a median follow-up time of 54.4 months (interquartile range, 38.8-71.8). Patients with pulmonary nodules indicated significantly increased rates of pulmonary metastasis, compared with patients without pulmonary nodules $(24.2$ vs. $6.1 \%$; $\mathrm{P}<0.001)$. In multivariate analysis, the presence of pulmonary nodules [hazard ratio $(\mathrm{HR})=3.15 ; \mathrm{P}=0.0262$ ], albumin $(\mathrm{HR}=0.42$; $\mathrm{P}=0.0490)$ and pTstage $(\mathrm{HR}=3.63 ; \mathrm{P}=0.0475)$ were indicated to be independent prognostic markers for pulmonary metastasis. In subgroup analysis, pTstage was the only independent prognostic indicator for pulmonary metastasis in these patients $(\mathrm{HR}=9.81 ; \mathrm{P}=0.0033)$. In patients with $\mathrm{RCC}$, the presence of
\end{abstract}

Correspondence to: Professor Hong Koo Ha, Department of Urology, Pusan National University Hospital, Pusan National University School of Medicine, 179 Gudeok-ro, Seo-gu, Busan 49241, Republic of Korea

E-mail: hongkooha@naver.com

*Contributed equally

Key words: multiple pulmonary nodules, neoplasm metastasis, nephrectomy, prognostic factors, pulmonary cancer, renal cell carcinoma pulmonary nodules was associated with pulmonary metastasis. Furthermore, pTstage is a negative prognostic indicator in patients with pulmonary nodules. Therefore, a chest radiologic short-term follow-up is required for these patients.

\section{Introduction}

Since the 1970s, the incidence of renal cell carcinoma (RCC) has increased by an annual mean rate of $3-4 \%$, which in turn was associated with a more prevalent use of various radiological imaging methods for the evaluation of diverse abdominal problems $(1,2)$. It has been reported that $20-30 \%$ of patients with RCC exhibit metastatic RCC (3). In addition, $20-30 \%$ of patients who undergo nephrectomy for clinically localized disease progressively metastasize during follow-ups (4). Therefore, when RCC is diagnosed, it is necessary to evaluate the presence or absence of metastasis. The foremost metastatic site of RCC is the lung, which is involved in $45-75 \%$ of metastatic cases (5). Therefore, when determining the presence or absence of metastasis from RCC, the first priority should be to evaluate pulmonary metastasis.

In a number of cases, at the time of RCC diagnosis, pulmonary nodules were detected through chest radiological imaging (6-8). The significance of these pulmonary nodules remains unclear. Additionally, these pulmonary nodules are frequently defined as indeterminate by radiologists and are generally too small to perform percutaneous biopsy (9). Therefore, physicians and patients have not demonstrated a notable interest in these pulmonary nodules. However, pulmonary nodules may serve an important role in lung metastasis. Non-calcified pulmonary nodules may represent metastatic disease in $19 \%$ of patients diagnosed with cancer (10). Evidently, this association, to the best of our knowledge, has not been noticed nor studied in detail. Despite the association between pulmonary nodules and lung cancer, pulmonary nodules located through preoperative chest radiological imaging are frequently overlooked, and their presence generally does not influence postoperative follow-up protocols. Current American Urological Association guidelines for the follow-up imaging (radiography and chest) of patients who undergo surgery for 
clinically localized renal masses are based on disease risk as defined by the pathologic tumor stage (11), emphasizing its overall importance. The purpose of the present study was to outline and elaborate prognostic indicators of pulmonary metastasis and to clarify the association between pulmonary nodules and pulmonary metastasis in patients with RCC.

\section{Patients and methods}

Patient population. This was a retrospective study, and the study protocols were approved by the Medical Ethics Committee of the Institutional Review Board of Pusan National University Hospital (Busan, Korea). Out of the 1,011 patients diagnosed with RCC, the present study included 383 patients, who had undergone radical or partial nephrectomy for RCC at the Pusan National University Hospital between 2011 and 2016. The probability of lung metastasis for each lesion was evaluated with a two-point confidence scale, with Fig. 1 representing a metastatic lesion, and Fig. 2 representing a benign or indeterminate lesion. On the chest computed tomographic (CT) image, the metastatic nodule was characterized as a lesion with a well-circumscribed border, round shape, soft tissue attenuation and/or multiplicity. Therefore, during imaging analysis, the binary values were assigned for the characterization of the pulmonary nodule. Nodules exhibiting features of metastatic nodule were assigned to 1 , whereas nodules exhibiting benign or indeterminate features were assigned to $2(5,10,12)$. The last follow-up was conducted on March 31st 2018. Exclusion criteria for the patient sample collection were as follows: Patients who underwent chemotherapy; patients who did not undergo renal resection or preoperative chest CT; and patients who were already diagnosed with pulmonary metastasis prior to surgery. Following surgery, patients who were diagnosed by pathology as benign tumor in the kidney were excluded from the present study (Fig. 3).

The data from 356 patients, 243 male and 113 female patients $(59.3 \pm 12.3$ and $58.1 \pm 12.3$, respectively) were used and patients were divided into the following 2 groups: Absent $(n=323)$ and present $(n=33)$, according to the status of pulmonary metastasis. Patient characteristics were examined, including age, sex, body mass index (BMI), presence of pulmonary nodules, smoking status, diabetes mellitus (DM), hypotension (HTN), renal tumor size, renal tumor site, renal tumor location, renal vein thrombus status, serum creatinine levels, albumin, lactate dehydrogenase (LDH), hemoglobin, calcium, potassium, symptomatic flank pain, pathologic T stage (pTstage), pathologic N stage, histologic subtype (clear cell vs. non-clear cell), lymphovascular invasion, presence of sarcomatoid cells and renal fat invasion status, using the patients' medical records. The patients underwent chest CT every 3-6 months following renal surgery. If pulmonary nodules were detected through preoperative chest CT, the size, number, site, and location of the nodules was examined. The size of the pulmonary nodules was defined as the longest diameter on an axial image. Following surgery, pathology reports were used to determine the tumor-node-metastasis classification (11) of malignant tumors and the histologic subtype. Written informed consent was obtained from all patients prior to enrollment in the study, in addition to explaining its purpose and methods.
Statistical analysis. An Continuous variables were described by mean \pm standard deviation and median (range), and qualitative variables by size and percentage. Independent Student's t-test was used for numerical patient data, including age, $\mathrm{BMI}$, renal tumor size, serum creatinine, albumin, $\mathrm{LDH}$, hemoglobin, calcium, potassium, and pulmonary nodule size. Fisher's exact test or $\chi^{2}$ test was used for categorical data, including sex, presence of pulmonary nodule, smoking status, DM, HTN, renal tumor site and location, renal vein thrombus, symptomatic flank pain, the number, site and location of pulmonary nodules, pathological tumor and lymph node stages, histologic subtype, lymphovascular invasion, presence of sarcomatoid cells and renal fat invasion status. Univariate and multivariate logistic regression analyses and log-rank test were used to assess the association between each of the factors and progression to pulmonary metastasis. $\mathrm{P}<0.05$ was considered to indicate a statistically significant difference. All data were analyzed using SPSS 20.0 software (IBM Corp., Armonk, NY, USA).

\section{Results}

Clinicopathological characteristics. A total of 1,011 patients with RCC diagnosed by abdomen CT were included in the present study. Among these, 383 patients underwent radical nephrectomy, and 356 patients were included in the criteria. The median follow-up duration was 54.4 months (interquartile range, 38.8-71.8). At the time of the last follow-up, pulmonary nodules were absent from 294 patients and present in 62 patients. Table I includes the patient characteristics of the two groups (with and without pulmonary metastasis). Patients with pulmonary metastasis indicated statistically significant results for the following: Age $(\mathrm{P}=0.011)$, larger renal tumor size $(\mathrm{P}=0.005)$, renal vein thrombus $(\mathrm{P}<0.001)$, median albumin $(\mathrm{P}=0.002)$, pTstage $(\mathrm{P}<0.001)$, pNstage $(\mathrm{P}<0.001)$, renal fat invasion $(\mathrm{P}<0.001)$, and the status of pulmonary nodule $(\mathrm{P}<0.001)$. In addition, pulmonary metastasis was observed in $24 \%$ of patients with pulmonary nodules. There were no statistically significant differences between the two groups in other factors regarding pulmonary nodule size.

The factors associated with pulmonary metastasis in patients with $R C C$. The results of univariate and multivariate logistic regression analyses on progression to pulmonary metastasis in the groups of patients with RCC are displayed in Table II. In univariate logistic regression analysis, progression to pulmonary metastasis was significantly associated with age [hazard ratio $(\mathrm{HR})=1.03 ; 95 \%$ confidence interval (CI), 1.00-1.07; $\mathrm{P}=0.0410]$, pulmonary nodules $(\mathrm{HR}=4.89$; 95\% CI, 2.29-10.39; $\mathrm{P}<0.001)$, renal tumor size $(\mathrm{HR}=1.02$; $95 \% \mathrm{CI}, 1.01-1.03 ; \mathrm{P}=0.0007)$, renal vein thrombus $(\mathrm{HR}=9.08$; 95\% CI, 2.48-32.03; $\mathrm{P}=0.0005)$, albumin $(\mathrm{HR}=0.41 ; 95 \% \mathrm{CI}$, 0.21-0.81; $\mathrm{P}=0.0094)$, pTstage $(\mathrm{HR}=8.96 ; 95 \% \mathrm{CI}, 4.01-20.49$; $\mathrm{P}<0.001)$, and renal fat invasion $(\mathrm{HR}=5.83 ; 95 \% \mathrm{CI}, 2.14-15.13$; $\mathrm{P}=0.0004)$. In multivariate logistic regression analysis, pulmonary nodule $(\mathrm{HR}=3.15 ; 95 \% \mathrm{CI}, 1.12-8.68 ; \mathrm{P}=0.0262)$, albumin $(\mathrm{HR}=0.42 ; 95 \% \mathrm{CI}, 0.17-1.03 ; \mathrm{P}=0.0490)$ and pTstage ( $\mathrm{HR}=3.63 ; 95 \% \mathrm{CI}, 0.98-12.86 ; \mathrm{P}=0.0475)$ were significantly associated with pulmonary metastasis. According to the Kaplan-Meier curves, there was a strong difference $(\mathrm{P}<0.001)$ 


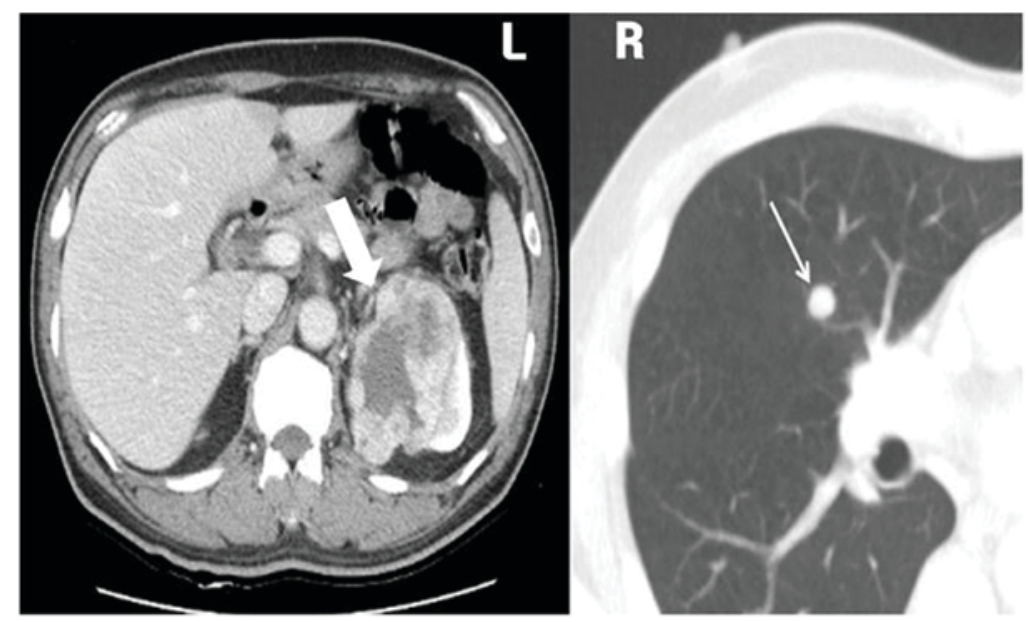

Figure 1. CT scans of metastatic nodule in a 57-year-old male patient. Thick arrow, abdominal CT image demonstrates $8.7 \mathrm{~cm}$ sized heterogeneous enhancing mass with central necrosis, left kidney, indicative of renal cell carcinoma. Thin arrow, chest CT scan indicates a $1 \mathrm{~cm}$-sized nodule with well-circumscribed border and round shape, representing a metastatic nodule. CT, computed tomography.
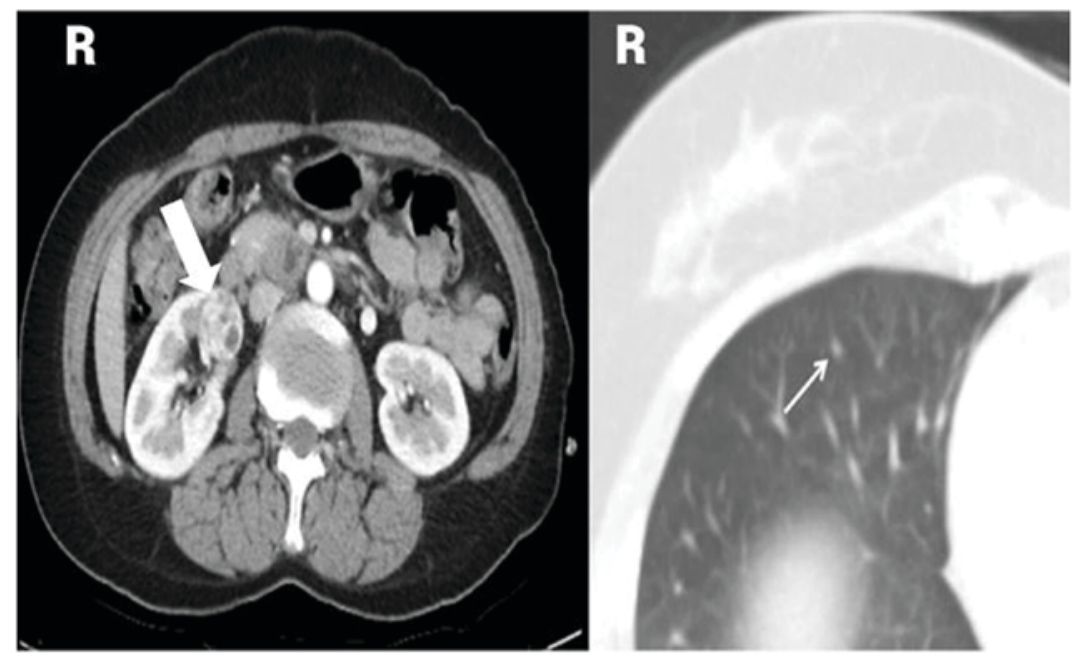

Figure 2. CT scans of pulmonary nodule in a 47-year-old female patient. Thick arrow, abdominal CT image (right side) indicated a $2.5 \mathrm{~cm}$ sized heterogeneous enhancing mass, right kidney, indicative of renal cell carcinoma. Thin arrow, chest CT scan indicating $5 \mathrm{~mm}$ sized nodule with ill-defined borders, indicative of benign-looking nodule. CT, computed tomography.

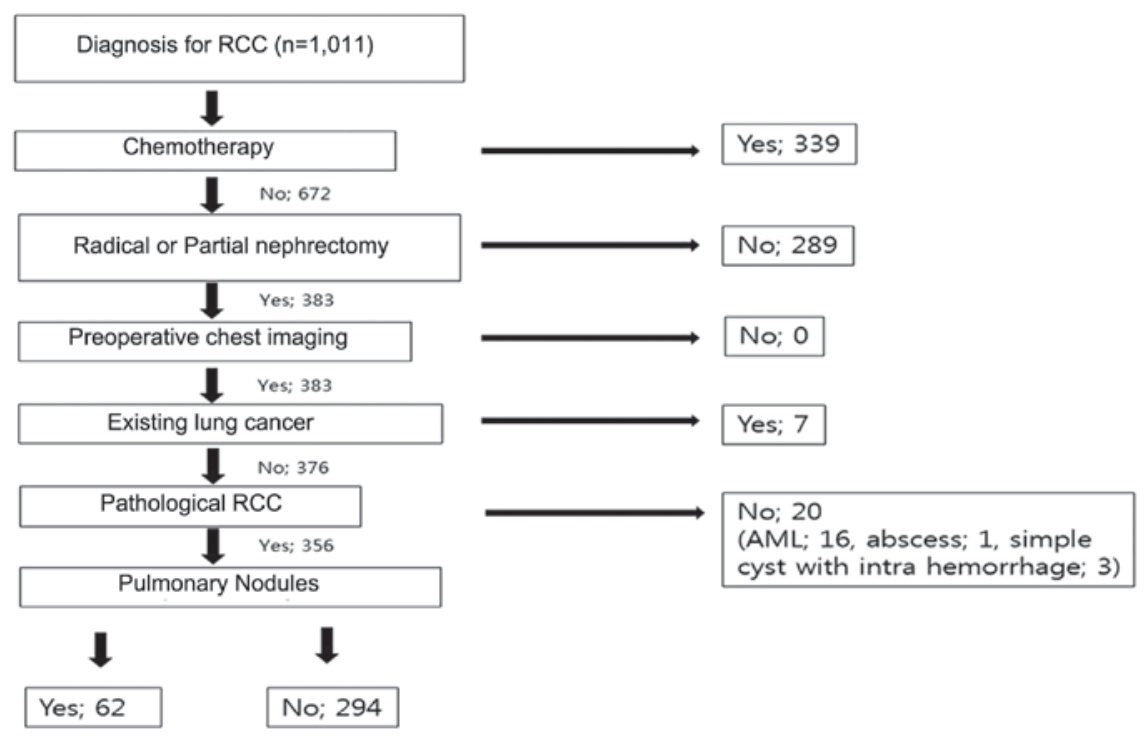

Figure 3. Patient selection flowchart. RCC, renal cell carcinoma; AML, angiomyolipoma. 
Table I. Clinicopathological characteristics of 356 patients with renal cell carcinoma treated with nephrectomy.

\begin{tabular}{|c|c|c|c|c|}
\hline \multirow[b]{2}{*}{ Variables } & \multirow[b]{2}{*}{ Total } & \multicolumn{2}{|c|}{ Pulmonary metastasis } & \multirow[b]{2}{*}{ P-value } \\
\hline & & Absent & Present & \\
\hline Number of patients, (\%) & 356 & $323(90.7)$ & $33(9.3)$ & \\
\hline Median age \pm SD (years) & $58.9 \pm 12.3$ & $58.4 \pm 12.5$ & $63.1 \pm 9.2$ & 0.011 \\
\hline Sex n, (\%) & & & & 0.992 \\
\hline Male & $243(68.3)$ & $221(68.4)$ & $22(66.7)$ & \\
\hline Female & $113(31.7)$ & $102(31.6)$ & $11(33.3)$ & \\
\hline Median $\mathrm{BMI} \pm \mathrm{SD}\left(\mathrm{kg} / \mathrm{m}^{2}\right)$ & $24.1 \pm 3.4$ & $24.1 \pm 3.4$ & $24.2 \pm 3.8$ & 0.941 \\
\hline Pulmonary nodule, n (\%) & & & & $<0.001$ \\
\hline Absent & $294(82.6)$ & $276(85.4)$ & $18(54.5)$ & \\
\hline Present & $62(17.4)$ & $47(14.6)$ & $15(45.5)$ & \\
\hline Smoker, n (\%) & & & & 0.925 \\
\hline Absent & $256(71.9)$ & $233(72.1)$ & $23(69.7)$ & \\
\hline Present & $100(28.1)$ & $90(27.9)$ & $10(30.3)$ & \\
\hline $\mathrm{DM}, \mathrm{n}(\%)$ & & & & 1.000 \\
\hline Absent & $311(87.4)$ & $282(87.3)$ & $29(87.9)$ & \\
\hline Present & $45(12.6)$ & $41(12.7)$ & $4(12.1)$ & \\
\hline HTN, n (\%) & & & & 1.000 \\
\hline Absent & $221(62.1)$ & $201(62.2)$ & $20(60.6)$ & \\
\hline Present & $135(37.9)$ & $122(37.8)$ & $13(39.4)$ & \\
\hline Median renal tumor size \pm SD $(\mathrm{mm})$ & $38.9 \pm 24.2$ & $37.3 \pm 23.0$ & $53.6 \pm 30.7$ & 0.005 \\
\hline Renal tumor site, $\mathrm{n}(\%)$ & & & & 0.948 \\
\hline Right & $160(46.0)$ & $145(46.5)$ & $15(47.4)$ & \\
\hline Left & $188(54.0)$ & $170(53.5)$ & $18(52.6)$ & \\
\hline Renal tumor location, n (\%) & & & & 0.249 \\
\hline Upper & $109(32.6)$ & $94(31.2)$ & $15(45.5)$ & \\
\hline Middle & $132(39.5)$ & 121 (40.2.) & $11(33.3)$ & \\
\hline Lower & $93(27.8)$ & $86(28.6)$ & $7(21.2)$ & \\
\hline Renal vein thrombus, $\mathrm{n}(\%)$ & & & & $<0.001$ \\
\hline Absent & $333(96.8)$ & $305(98.1)$ & $28(84.8)$ & \\
\hline Present & $11(3.2)$ & $6(1.9)$ & $5(15.2)$ & \\
\hline Median creatinine $\pm \mathrm{SD}(\mathrm{mg} / \mathrm{dl})$ & $1.1 \pm 1.0$ & $1.1 \pm 1.1$ & $1.0 \pm 0.3$ & 0.228 \\
\hline Median albumin \pm SD (g/dl) & $3.7 \pm 0.6$ & $3.7 \pm 0.6$ & $3.5 \pm 0.4$ & 0.002 \\
\hline Median LDH \pm SD (IU/l) & $225.9 \pm 87.5$ & $226.4 \pm 88.3$ & $220.9 \pm 84.0$ & 0.837 \\
\hline Median hemoglobin $\pm \mathrm{SD}(\mathrm{g} / \mathrm{dl})$ & $12.4 \pm 1.6$ & $12.4 \pm 1.6$ & $11.9 \pm 1.8$ & 0.074 \\
\hline Median calcium $\pm \mathrm{SD}(\mathrm{mg} / \mathrm{dl})$ & $8.4 \pm 0.7$ & $8.4 \pm 0.7$ & $8.5 \pm 0.7$ & 0.389 \\
\hline Median $\mathrm{K} \pm \mathrm{SD}(\mathrm{mmol} / \mathrm{l})$ & $4.1 \pm 0.5$ & $4.1 \pm 0.5$ & $4.0 \pm 0.5$ & 0.822 \\
\hline Symptomatic flank pain, n (\%) & & & & 0.246 \\
\hline Absent & $337(96.0)$ & 308 (96.6) & $29(90.6)$ & \\
\hline Present & $14(4.0)$ & $11(3.4)$ & $3(9.4)$ & \\
\hline Median pulmonary nodule size $\pm \mathrm{SD}(\mathrm{mm})$ & $9.0 \pm 8.5$ & $8.4 \pm 8.9$ & $10.7 \pm 6.9$ & 0.359 \\
\hline Pulmonary nodule number, n (\%) & & & & 0.130 \\
\hline 1 & $33(53.2)$ & $25(53.2)$ & $8(53.3)$ & \\
\hline 2 & $14(22.6)$ & $13(27.7)$ & $1(6.7)$ & \\
\hline 3 & $1(1.6)$ & $1(2.1)$ & $0(0.0)$ & \\
\hline 4 & $0(0.0)$ & $0(0.0)$ & $0(0.0)$ & \\
\hline 5 & $1(1.6)$ & $0(0.0)$ & $1(6.7)$ & \\
\hline$>5$ & $13(21.0)$ & $8(17.0)$ & $5(33.3)$ & \\
\hline
\end{tabular}


Table I. Continued.

\begin{tabular}{|c|c|c|c|c|}
\hline \multirow[b]{2}{*}{ Variables } & \multirow[b]{2}{*}{ Total } & \multicolumn{2}{|c|}{ Pulmonary metastasis } & \multirow[b]{2}{*}{ P-value } \\
\hline & & Absent & Present & \\
\hline Pulmonary nodule site, n (\%) & & & & 0.958 \\
\hline Right & $21(33.9)$ & $18(36.0)$ & $3(25.0)$ & \\
\hline Left & $18(29.0)$ & $15(30.0)$ & $3(25.0)$ & \\
\hline Bilateral & $23(37.1)$ & $17(34.0)$ & $6(50.0)$ & \\
\hline Pulmonary nodule location, n (\%) & & & & 0.394 \\
\hline Lower & $11(17.7)$ & $10(21.3)$ & $1(6.7)$ & \\
\hline Middle & $6(9.7)$ & $5(10.6)$ & $1(6.7)$ & \\
\hline Upper & $23(37.1)$ & $15(31.9)$ & $8(53.3)$ & \\
\hline Multiple & $22(35.5)$ & $17(36.2)$ & $5(33.3)$ & \\
\hline${ }^{1} \mathrm{pT}$ stage, $\mathrm{n}(\%)$ & & & & $<0.001$ \\
\hline pT1-T2 & $239(82.7)$ & $226(87.3)$ & $13(43.3)$ & \\
\hline pT3-T4 & $50(17.3)$ & $33(12.7)$ & $17(56.7)$ & \\
\hline${ }^{2} \mathrm{pN}$ stage, $\mathrm{n}(\%)$ & & & & $<0.001$ \\
\hline $\mathrm{pNO}$ & $214(82.9)$ & $200(86.2)$ & $14(53.8)$ & \\
\hline pN1 (27) & $44(17.1)$ & $32(13.8)$ & $12(46.2)$ & \\
\hline Histologic subtype, n (\%) & & & & 0.237 \\
\hline Clear cell & $241(83.7)$ & $214(82.6)$ & $27(93.1)$ & \\
\hline Non-clear cell & $47(16.3)$ & $45(17.4)$ & $2(6.9)$ & \\
\hline Lymphovascular invasion, $\mathrm{n}(\%)$ & & & & 0.107 \\
\hline Absent & $277(92.6)$ & $251(93.7)$ & $26(83.9)$ & \\
\hline Present & $22(7.4)$ & $17(6.3)$ & $5(16.1)$ & \\
\hline Sarcomatoid differentiation, n (\%) & & & & 0.960 \\
\hline Absent & $273(98.2)$ & $248(98.4)$ & $25(96.2)$ & \\
\hline Present & $5(1.8)$ & $4(1.6)$ & $1(3.8)$ & \\
\hline Renal fat invasion, $\mathrm{n}(\%)$ & & & & $<0.001$ \\
\hline Absent & $241(90.6)$ & $223(92.9)$ & $18(69.2)$ & \\
\hline Present & $25(9.4)$ & $17(7.1)$ & $8(30.8)$ & \\
\hline
\end{tabular}

${ }^{1}$ pTstage, pathologic tumor stage; ${ }^{2} \mathrm{pNstage}$, pathologic lymph node vascular invasion; SD, standard deviation; BMI, body mass index; DM, diabetes mellitus; HTN, hypotension; LDH, lactate dehydrogenase; pTstage, pathologic T stage.

in progression to pulmonary metastasis in patients with pulmonary nodules, compared with patients without pulmonary nodules (Fig. 4).

The factors associated with pulmonary metastasis in patients with RCC pulmonary nodule. In subgroup analysis, the risk factors associated with pulmonary metastasis were examined in patients with pulmonary nodules. In univariate logistic regression analysis, renal tumor size $(\mathrm{HR}=1.02 ; 95 \% \mathrm{CI}, 1.00-1.04$; $\mathrm{P}=0.0356)$, albumin $(\mathrm{HR}=0.12 ; 95 \% \mathrm{CI}, 0.02-0.46 ; \mathrm{P}=0.0046)$, pTstage $(\mathrm{HR}=11.89 ; 95 \% \mathrm{CI}, 3.04-55.33 ; \mathrm{P}=0.0007)$ and renal fat invasion $(\mathrm{HR}=11.14 ; 95 \% \mathrm{CI}, 2.39-63.86 ; \mathrm{P}=0.0032)$ were significantly associated with pulmonary metastasis. In multivariate logistic regression analysis, pTstage was the only statistically significant factor for pulmonary metastasis ( $\mathrm{HR}=9.81 ; 95 \% \mathrm{CI}, 2.29-51.30 ; \mathrm{P}=0.0033)$. No other significant differences in the remaining variables were indicated between groups (Table III).

\section{Discussion}

In the present study, 62/356 patients (17.4\%) with RCC exhibited pulmonary nodules, and $15 / 62$ patients $(24.2 \%)$ progressed to pulmonary metastasis. The prevalence of progression to pulmonary metastasis was significantly increased in patients with pulmonary nodules, compared with patients without pulmonary nodules. In multivariate analysis, the presence of pulmonary nodules was an independent prognostic factor for pulmonary metastasis and was associated with adverse effects associated with progression to pulmonary metastasis. Among patients with pulmonary nodules, progression to pulmonary metastasis occurred at a $>3$-fold increased rate, compared with patients without pulmonary nodules. Taking the aforementioned into consideration, pulmonary nodules in patients with RCC are indicated to be prognostic indicators of pulmonary metastasis. Even though pulmonary nodules were a significant factor 
Table II. Prognostic indicators for progression to pulmonary metastasis in patients with renal cell carcinoma.

\begin{tabular}{lcccccc}
\hline & \multicolumn{3}{c}{ Univariate analysis } & & \multicolumn{2}{c}{ Multivariate analysis } \\
\cline { 2 - 5 } Factors & P-value & HR & $95 \%$ CI & & P-value & HR \\
\hline Age & 0.0410 & 1.03 & $1.00-1.07$ & 0.0735 & 1.04 & $1.00-1.10$ \\
Pulmonary nodule & $<0.001$ & 4.89 & $2.29-10.39$ & 0.0262 & 3.15 & $1.12-8.68$ \\
Renal tumor size & 0.0007 & 1.02 & $1.01-1.03$ & 0.2702 & 1.01 \\
Renal vein thrombus & 0.0005 & 9.08 & $2.48-32.03$ & 0.9032 & 1.11 & $0.99-1.03$ \\
Albumin & 0.0094 & 0.41 & $0.21-0.81$ & 0.0490 & 0.42 & $0.17-1.03$ \\
1 pTstage (25) & $<0.001$ & 8.96 & $4.01-20.49$ & 0.0475 & 3.63 & $0.98-12.86$ \\
Renal fat invasion & 0.0004 & 5.83 & $2.14-15.13$ & 0.6316 & 1.41 & $0.33-5.87$ \\
\hline
\end{tabular}

${ }^{1}$ pTstage, pathologic tumor stage; HR, hazard ratio; CI, confidence interval.

Table III. Prognostic indicators for progression to pulmonary metastasis in patients with renal cell carcinoma with pulmonary nodule.

\begin{tabular}{|c|c|c|c|c|c|c|}
\hline \multirow[b]{2}{*}{ Factors } & \multicolumn{3}{|c|}{ Univariate analysis } & \multicolumn{3}{|c|}{ Multivariate analysis } \\
\hline & P-value & HR & $95 \% \mathrm{CI}$ & P-value & HR & $95 \% \mathrm{CI}$ \\
\hline Age & 0.1839 & 1.04 & $0.98-1.11$ & & & \\
\hline Renal tumor size & 0.0356 & 1.02 & $1.00-1.04$ & & & \\
\hline Renal vein thrombus & 0.1394 & 3.67 & $0.61-22.15$ & & & \\
\hline Albumin & 0.0046 & 0.12 & $0.02-0.46$ & 0.0781 & 0.20 & $0.03-1.14$ \\
\hline${ }^{1}$ pTstage & 0.0007 & 11.89 & $3.04-55.33$ & 0.0033 & 9.81 & $2.29-51.30$ \\
\hline Renal fat invasion & 0.0032 & 11.14 & 2.39-63.86 & & & \\
\hline
\end{tabular}

${ }^{1}$ pTstage, pathologic tumor stage; HR, hazard ratio; CI, confidence interval.

in progression to pulmonary metastasis, when preoperative pulmonary nodules are detected, no clinical management strategy has been developed, to the best of our knowledge, until now (13). A number of previous studies have indicated that larger kidney tumors, renal vein thrombus, lymph node vascular invasion and renal fat invasion increase the adverse effects of cancer and poor prognosis by increasing the likelihood of malignancy or recurrence (14-16). Additionally, there are significant risk factors associated with the presence of pulmonary nodules, the pathologic tumor stage and tumor grade, which can be used to predict a poor prognosis (17-19). These factors were statistically significant in univariate analysis in the present study, but pulmonary nodules were the most statistically significant factor in multivariate analysis.

In the present study's subgroup analysis, including pulmonary nodules, it was indicated that renal tumor size, albumin level, pTstage and renal fat invasion were significantly associated with pulmonary metastasis in univariate analyses. Chen et al (20) reported that albumin is an important prognostic indicator in patients with RCC, regardless of tumor type (localized or metastatic). Cancer is frequently accompanied by malnutrition and chronic inflammation, and albumin levels are associated with the degree of malnutrition or inflammatory response $(21,22)$.

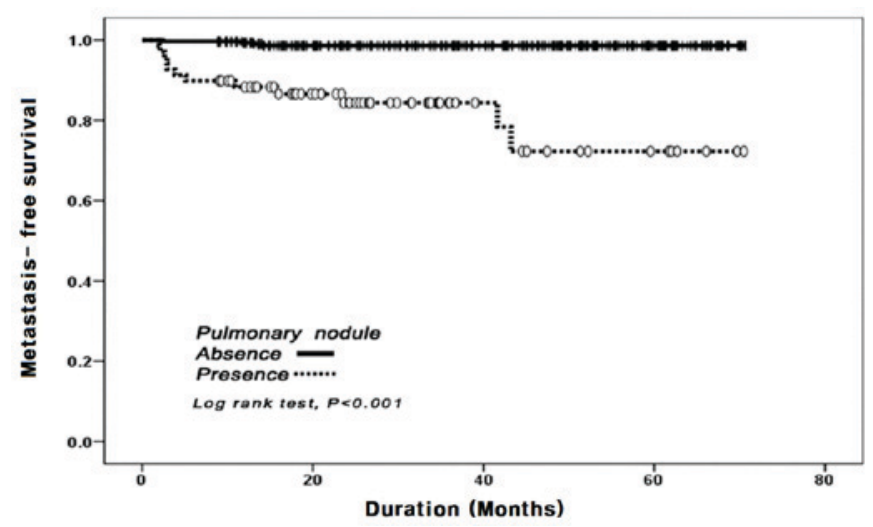

Figure 4. Time to pulmonary metastasis-free survival based on the status of pulmonary nodules.

Furthermore, pTstage was a significant prognostic indicator, consistent with previous reports $(17,18)$. In multivariate analyses, pTstage was the only independent prognostic indicator for pulmonary metastasis. The size (median size $>5 \mathrm{~mm}$ ) and number (median number $>4$ ) of pulmonary nodules have been reported to be increased in patients with pulmonary metastasis compared with patients with no pulmonary metastasis $(13,23)$. However, the size, number, site and location of pulmonary 
nodules were not associated with pulmonary metastasis in the present study. Therefore, the presence of a pulmonary nodule is a strong prognostic indicator for pulmonary metastasis in patients with RCC. Additionally, in patients with pulmonary nodules, pTstage was a good prognostic indicator for pulmonary metastasis. Nevertheless, recent guidelines for follow-up imaging (chest and radiography) by $\mathrm{CT}$ or X-ray of patients who underwent radical or partial nephrectomy (24) are based on the pathological tumor stage. Additionally, there are no definite guidelines for patients with pulmonary nodules (25). Therefore, the present study indicates that the presence of pulmonary nodules may be considered as an associated risk factor for chest radiological imaging follow-up, particularly in patients who underwent radical or partial nephrectomy. Additionally, follow-up imaging (chest and radiography) by CT or X-ray should be performed more frequently, compared with the Fleischner Society guidelines (12). Evidently, short-term follow-up imaging may not be necessary for patients who have not been diagnosed with RCC. Benjamin et al (26) reported that the malignancy rate in small nodules in patients without a known malignant tumor may be as low as $1 \%$.

There are numerous strengths in the present study. Firstly, the present study presents a large number of registered patients compared with other reports $(13,19)$, which could reduce selection bias. Secondly, a more extensive analysis of patient data, compared with other reports $(3,10,23)$, was conducted by examining various factors from the patient's history to blood test, preoperative imaging and postoperative pathology results, including hypertension, renal tumor site and location, pulmonary nodule number, site and location, and serum $\mathrm{K}$ level. Thirdly, in another study, the nodule was diagnosed by chest CT or X-ray and follow-up $(13,19)$, in contrast to the present study where patients were diagnosed and followed up by chest CT. However, the present study does present a number of limitations. Firstly, it was a retrospective analysis at a single center; therefore, selection bias may have affected the progression to pulmonary metastasis. Secondly, the precise time that the pulmonary nodules changed to malignant tumors could not be confirmed, due to the postoperative chest CT imaging follow-ups not being consistent. Nevertheless, the fact that the presence of pulmonary nodules is associated with progression to pulmonary metastasis is of notable value, as they may be stronger risk factors, compared with other preoperative factors. The presence of pulmonary nodules is an important prognostic indicator to consider in the diagnosis and management of patients with RCC.

In conclusion, in patients with RCC who underwent radical or partial nephrectomy, patients with pulmonary nodules had a significantly increased probability of progression to pulmonary metastasis, compared with patients without pulmonary nodules. Additionally, in patients with pulmonary nodules, pTstage was significantly associated with progression to pulmonary metastasis. Further studies involving a more aggressive short-term chest radiography follow-up are required for patients with RCC with pulmonary nodules or higher pTstages.

\section{Acknowledgements}

Not applicable.

\section{Funding}

No funding was received.

\section{Availability of data and materials}

The datasets used and/or analyzed during the current study are available from the corresponding author on reasonable request.

\section{Authors' contributions}

JYK, JGL and HKH analyzed the data and contributed to the conception and design of the present study. JYK, JGL, CHL and $\mathrm{SHC}$ assisted in the acquisition, analysis and interpretation of data. CHL, HKH and SHC were involved in drafting the manuscript and revising it critically for intellectual content. SK and SBH confirmed the preoperative and postoperative chest CT. HKH and SHC gave final approval for the publication of the final version of the manuscript following overall revision. All authors have read and approved the final version of the manuscript.

\section{Ethics approval and consent to participate}

The present study was appoved by the Pusan National University Hospital Institutional Review Board (approval no. 1802-004-063). Written informed consent was obtained from all patients prior to enrollment in the study.

\section{Patient consent for publication}

Not applicable.

\section{Competing interests}

The authors declare that they have no competing interests.

\section{References}

1. Kummerlin IP, ten Kate FJ, Wijkstra H, de la Rosette JJ and Laguna MP: Changes in the stage and surgical management of renal tumours during 1995-2005: An analysis of the Dutch national histopathology registry. BJU Int 102: 946-951, 2008.

2. Chang JS, Park YH, Ku JH, Kwak C and Kim HH: Predicting factors for death from other causes in patients with localized renal cell carcinoma. Korean J Urol 53: 18-22, 2012.

3. Mano R, Vertosick E, Sankin AI, Chevinsky MS, Larish Y, Jakubowski CD, Hötker AM, Hakimi AA, Sjoberg DD, Akin O and Russo P: Subcentimeter pulmonary nodules are not associated with disease progression in patients with renal cell carcinoma. J Urol 193: 776-82, 2015.

4. Ljungberg B: The role of metastasectomy in renal cell carcinoma in the era of targeted therapy. Curr Urol Rep 14: 19-25, 2013.

5. Bianchi M, Sun M, Jeldres C, Shariat SF, Trinh QD, Briganti A, Tian Z, Schmitges J, Graefen M, Perrotte P, et al: Distribution of metastatic sites in renal cell carcinoma: A population-based analysis. Ann Oncol 23: 973-980, 2012.

6. Ueda K, Suekane S, Mitani T, Chikui K, Ejima K, Suyama S, Nakiri M, Nishihara K, Matsuo M and Igawa T: Spontaneous regression of multiple pulmonary nodules in a patient with unclassified renal cell carcinoma following laparoscopic partial nephrectomy: A case report 5. Mol Clin Oncol 5: 49-52, 2016.

7. Phua CK, Sim WY, Sen Tee K, Lew SJ, Lim AY, Tai DY, Goh SK, Kor AC, Ng AW, Abisheganaden J and Verma A: Evaluation of pulmonary nodules in Asian population. $\mathrm{J}$ Thorac Dis 8: 950-957, 2016. 
8. Field JK, Marcus MW and Oudkerk M: Risk assessment in relation to the detection of small pulmonary nodules. Transl Lung Cancer Res 6: 35-41, 2017.

9. Griffin N, Gore ME and Sohaib SA: Imaging in metastatic renal cell carcinoma. AJR Am J Roentgenol 189: 360-370, 2007.

10. Khokhar S, Vickers A, Moore MS, Mironov S, Stover DE and Feinstein MB: Significance of non-calcified pulmonary nodules in patients with extrapulmonary cancers. Thorax 61: 331-336, 2006.

11. Donat SM, Diaz M, Bishoff JT, Coleman JA, Dahm P, Derweesh IH, Herrell SD III, Hilton S, Jonasch E, Lin DW, et al: Follow-up for clinically localized renal neoplasms: AUA Guideline. J Urol 190:407-16, 2013.

12. MacMahon H, Austin JH, Gamsu G, Herold CJ, Jett JR, Naidich DP, Patz EF Jr and Swensen SJ; Fleischner Society: Guidelines for management of small pulmonary nodules detected on CT scans: A statement from the Fleischner Society. Radiology 237: 395-400, 2005.

13. Adibi M, Kenney PA, Thomas AZ, Borregales LD Nogueras-Gonzalez GM, Wang X, Devine CE, Karam JA and Wood CG: Prediction of pulmonary metastasis in renal cell carcinoma patients with indeterminate pulmonary nodules. Eur Urol 69: 352-360, 2016.

14. Mouracade P, Kara O, Maurice MJ, Dagenais J, Malkoc E, Nelson RJ and Kaouk JH: Patterns and predictors of recurrence after partial nephrectomy for kidney tumors. J Urol 197: 1403-1409, 2017.

15. Katz MD, Serrano MF, Humphrey PA, Grubb RL III, Skolarus TA, Gao F and Kibel AS: The role of lymphovascular space invasion in renal cell carcinoma as a prognostic marker of survival after curative resection. Urol Oncol 29: 738-744, 2011.

16. Abel EJ, Margulis V, Bauman TM, Karam JA, Christensen WP, Krabbe LM, Haddad A, Golla V and Wood CG: Risk factors for recurrence after surgery in non-metastatic RCC with thrombus: A contemporary multicentre analysis. BJU Int 117: E87-E94, 2016.

17. Adamy A, Chong KT, Chade D, Costaras J, Russo G, Kaag MG, Bernstein M, Motzer RJ and Russo P: Clinical characteristics and outcomes of patients with recurrence 5 years after nephrectomy for localized renal cell carcinoma. J Urol 185: 433-438, 2011
18. Sun M, Shariat SF, Cheng C, Ficarra V, Murai M, Oudard S, Pantuck AJ, Zigeuner R and Karakiewicz PI: Prognostic factors and predictive models in renal cell carcinoma: A contemporary review. Eur Urol 60: 644-661, 2011.

19. Xu R, Horick N, McGovern FJ, Dahl DM, Feldman AS, Blute ML, Olumi AF and Michaelson MD: Prognostic significance of indeterminate lung nodules in renal cell carcinoma. Urol Oncol 32: 355-361, 2014.

20. Chen Z, Shao Y, Wang K, Cao W, Xiong Y, Wu R, Luo S, Xu X and $\mathrm{He} \mathrm{X}$ : Prognostic role of pretreatment serum albumin in renal cell carcinoma: A systematic review and meta-analysis. Onco Targets Ther 9: 6701-6710, 2016.

21. Bauer J and Capra S: Comparison of a malnutrition screening tool with subjective global assessment in hospitalised patients with cancer-sensitivity and specificity. Asia Pac J Clin Nutr 12: 257-260, 2003

22. McMillan DC, Watson WS, O'Gorman P, Preston T, Scott HR and McArdle CS: Albumin concentrations are primarily determined by the body cell mass and the systemic inflammatory response in cancer patients with weight loss. Nutr Cancer 39: 210-213, 2001.

23. Henschke CI, Yankelevitz DF, Naidich DP, McCauley DI, McGuinness G, Libby DM, Smith JP, Pasmantier MW and Miettinen OS: CT screening for lung cancer: Suspiciousness of nodules according to size on baseline scans. Radiology 231: 164-168, 2004.

24. Gould MK, Fletcher J, Iannettoni MD, Lynch WR, Midthun DE, Naidich DP and Ost DE; American College of Chest Physicians: Evaluation of patients with pulmonary nodules: When is it lung cancer?: ACCP evidence-based clinical practice guidelines (2nd edition). Chest 132 (3 Suppl): 108S-130S, 2007.

25. Callister ME and Baldwin DR: How should pulmonary nodules be optimally investigated and managed? Lung Cancer 91: 48-55, 2016.

26. Benjamin MS, Drucker EA, McLoud TC and Shepard JA: Small pulmonary nodules: Detection at chest CT and outcome. Radiology 226: 489-493, 2003.

27. Sobin LH, Gospodariwicz M and Wittekind C: TNM classification of malignant tumors. UICC International Union Against Cancer. 7th ed. Wiley-Blackwell, 255, 2009. 